\title{
Escolas e professores no séc XXI: exigências, desafios, compromissos e respostas
}

\author{
Schools and teachers in the XXI century: demands, \\ challenges, commitments and answers
}

Escuelas y profesores de siglo. XXI: las demandas, desafíos, compromisos y respuestas

\section{Ariana Cosme*}

\section{Resumo}

A reflexão que se propõe neste texto constrói-se a partir da identificação de diversos tipos de discursos que se têm vindo a produzir sobre a ação docente e as possibilidades dos professores encontrarem um sentido para a profissão que abraçaram. Após se caraterizar os diferentes tipos de discursos identificados, reflete-se sobre os pressupostos e as implicações dos mesmos, denunciando-se equívocos e afirmando-se as potencialidades das narrativas que enfatizam a reflexividade docente como condição e suporte de um projeto

* AC: Doutora em Ciências da Educação, e-mail: ariana@fpce.up.pt 
de afirmação profissional congruente com os desafios e as exigências curriculares e pedagógicas das escolas do século XXI.

Palavras-chave: Identidade profissional docente. Ação docente. Reflexividade docente.

\begin{abstract}
The reflection that this text proposes, is built from the identification of various types of discourses that have been producing about teachers action and the possibilities for these one to find a meaning to the profession that they embraced. After the characterization of the different types of those discourses, is presented a reflection about the assumptions and implications of such discourses, denouncing the misconceptions and affirming the potential of the narratives that emphasize teacher reflexivity as a condition and support of a professional project that is congruent with the challenges and the curricular and pedagogical demands of schools in the twenty-first century.
\end{abstract}

Keywords: Teachers professional identity. Teacher action. Teacher reflexivity.

\title{
Resumen
}

La reflexión que propone este texto, se construye a partir de la identificación de los diferentes tipos de discursos que se han estado produciendo acerca de la acción docente y las posibilidades para los profesores encontrar un sentido para la profesión que han abrazado. Después de caracterizar aquellos discursos, se refleja en los supuestos y las implicaciones de los mismos, denunciando las ideas erróneas y afirmando el potencial de las narrativas que entendien la reflexividad docente como una condición y apoyo de un proyecto profesional congruente con los retos y las necesidades curriculares y pedagógicas de las escuelas en el siglo XXI.

Palabras-clave: Identidad profesional de los profesores. Actividad docente. Reflexividad docente. 


\section{Introdução}

Este é um texto no qual se pretende promover uma reflexão séria e sustentada acerca da possibilidade dos professores, hoje, poderem construir outros sentidos para a atividade que realizam, enquanto condição necessária ao processo da sua afirmação profissional no âmbito de escolas que, graças às transformações do mundo e da sociedade em que vivemos, os obrigam a confrontar-se quotidianamente com problemas de grande complexidade humana, técnica e científica.

De acordo com esta opção, pode-se considerar que me afasto das abordagens por meio das quais se pensa a configuração da profissão docente como algo que, hoje e em larga medida, escapa à ação profissional dos professores, de forma a poder abordar essa problemática em função de outra perspetiva e de outros parâmetros. Deste parâmetros importa mais do que inventariar obstáculos, definir o papel dos professores na definição da profissão que abraçaram, tendo em conta o modo como consideram, ou não, a existência desses obstáculos, o modo como lidam com eles e, finalmente, o modo como a partir do reconhecimento desses obstáculos definem as finalidades da ação que protagonizam e, neste âmbito, enunciam os seus compromissos profissionais. Não se pretende negar ou desvalorizar o peso de fatores de natureza extrínseca à Escola ou à ação dos professores na definição da profissão docente, o que se defende é que estes não poderão ser entendidos, à partida, como obstáculos, mas como desafios incontornáveis a enfrentar e problemáticas a discutir, enquanto fatores que contribuem, hoje, para configurar a atividade profissional dos professores como uma atividade em que se tem que "agir na urgência e a decidir na incerteza" (PERRENOUD, 2001).

Isto significa que a ação profissional dos docentes tem que ser entendida como uma ação sujeita a um determinado conjunto de constrangimentos políticos, sociais, culturais, institucionais, organizacionais, curriculares e pedagógicos que podendo condicioná-la não a determinam. É o caso, por exemplo, do reconhecimento da heterogeneidade dos alunos, entendida como um fator a gerir e a valorizar, mais do que um 
acontecimento negativo ou um facto a aceitar de forma condescendente e resignada. Até porque o processo de massificação escolar que o prolongamento da escolaridade obrigatória potenciou, é interpretado, no âmbito de uma tal abordagem, como um processo político, social e culturalmente desejável, ainda que se reconheça que a perda de "um público garantido e submisso, disponível para aprender o que lhe era exigido (ou para interiorizar, humildemente, que não eram capazes de aprender)" (CORTESÃO, 2000, p. 19), obriga a repensar as finalidades da acção educativa das escolas, as finalidades e os padrões de interação pedagógica e didática dos professores e o próprio estatuto profissional dos docentes na sequência e em articulação com o estatuto que se passa a atribuir aos alunos.

Admite-se, também, de acordo com os pressupostos que legitimam aquela mesma abordagem, que a necessidade de democratizar o acesso ao saber escolar é um desígnio que decorre da vida numa sociedade sujeita às exigências políticas, sociais e culturais e à aceitação dos princípios que organizam os regimes políticos democráticos. Daí que a democratização do "acesso ao conhecimento" (PERRENOUD, 1995, p. 17), obrigue a "diversificar as formas de acesso ao saber" (idem), por um lado, e, por outro, que se forneça "a cada um competências e uma cultura muito mais amplas" (idem, p. 20), finalidades que dependem, por um lado, do modo como os docentes forem capazes de "procurar estratégias mais convincentes de diferenciação do ensino e de avaliação formativa, e, por outro, de refletir sobre a pertinência dos conteúdos e das tarefas propostas aos alunos na perspetiva de aprendizagens fundamentais" (idem).

Em suma, uma visão proactiva da profissão docente não se resolve por si só, o conjunto dos problemas e dos dilemas com que se debatem hoje os professores permite enfrentá-los de forma mais sustentada e capaz, quer promovendo outras respostas no domínio da ação profissional propriamente dita quer estimulando uma reflexão consequente sobre as atribuições políticas e educativas, eventualmente excessivas, que possam constituir sustentáculo de uma perceção distinta quanto às efetivas responsabilidades pedagógicas e sociais dos docentes. 
Não estamos perante uma discussão e uma reflexão fáceis de realizar, ainda que devamos reconhecer que esta é uma discussão tão pertinente quanto obrigatória e que, por isso mesmo, poderá ser definida como a principal justificação que encontro para escrever este texto, no qual caraterizo os discursos de inspiração fatalista, os discursos voluntaristas e os discursos relacionados com a afirmação dos professores como profissionais reflexivos para interpelar os primeiros e os segundos, de forma a defender a necessidade de nos inspirarmos nos terceiros como contributo para abordar e pensar novas possibilidades de encontrar outros sentidos para a atividade docente.

\section{Os discursos sobre a ação docente: contributo para uma interpelação}

No quadro mais amplo da reflexão sobre o trabalho dos professores no âmbito das escolas em que vivemos é possível identificar três grandes tipos de discursos: (i) os discursos de inspiração fatalista; (ii) os discursos de inspiração voluntarista e (iii) os discursos relacionados com a necessidade dos professores se afirmarem como profissionais reflexivos.

Analisando estes tipos de discursos, constata-se que os primeiros exprimem o que poderá ser considerado uma perspetiva defensiva sobre a profissão docente, o que, neste caso, se exprime em função dos discursos de caráter conservador e os discursos de natureza corporativista, os quais, desenvolvendo-se em função de parâmetros e propósitos distintos, partilham de uma série de pressupostos comuns no domínio da reflexão que mobilizam acerca da docência como profissão.

Os discursos de carácter conservador afirmam-se, sobretudo, pela sua natureza elitista e nostálgica, defendendo que é por meio de medidas políticas educativas de largo espectro, as quais competirá aos ministérios da educação assumir, que se pode resolver o desencanto com que os professores encaram, hoje, a sua profissão. Assim sendo, e de acordo com tais discursos, seria importante, de acordo com esta perspetiva, que na legislação educativa se consagrasse novamente a utilização dos dispositivos explícitos de seleção académica como um contributo necessário à 
revalorização profissional da atividade docente. Para além disso, defendem, igualmente, que este processo de revalorização dependeria, também, da adoção de medidas as quais permitissem que os professores se afirmassem, no âmbito das salas de aula, em função de um tipo de autoridade pedagógica a qual deveria caracterizar-se por não admitir qualquer tipo de contestação. Quer o primeiro quer o segundo conjunto de medidas propostos possibilitaria, em última análise, ir excluindo progressivamente as crianças ditas "não educáveis" ${ }^{1}$ das escolas, o que constituiria, na versão conservadora, uma condição para resolver o mal-estar e o desencanto profissional dos professores. Os cenários propostos pelos discursos conservadores, que continuam a pensar as escolas como espaços suscetíveis de ser previamente objetivados quanto às atividades as quais neles ocorrem e aos papéis que, neste âmbito, os diversos protagonistas assumem, não conseguem, por isso, propor respostas viáveis para o sofrimento e o desencanto profissional dos professores. Um sofrimento e um desencanto que, de acordo com esta perspetiva, tendem a ser dissociados da existência de uma organização escolar que, muitas vezes, não está interessada, não sabe ou não é capaz de problematizar as finalidades que a justificam.

Os discursos de natureza corporativa que são credores das abordagens as quais tendem a entender a escola como um espaço de reprodução social (BOURDIEU, PASSERON, 2001; BAUDELOT, ESTABLET, 1975) distinguem-se e conflituam com os discursos conservadores no que diz respeito ao modo como entendem as funções política, social e educativa da Escola, ainda que se aproximem, de algum modo, destes últimos quanto ao modo como tendem a desresponsabilizar os professores nesse processo de redefinição da instituição escolar. Não são discursos que se constroem em função do mesmo plano de preocupações, até porque os

1 António Nóvoa é que nos recorda esta expressão utilizada por Maria José Nogueira Pinto num artigo publicado no semanário "Expresso", onde, de forma explícita, a articulista defende a necessidade de segregação escolar daqueles alunos que, segundo palavras suas, não se conseguirem salvar (NÓVOA, 2001). 
discursos de natureza corporativa aceitam que a Escola deve assumir um papel educativo de carácter mais amplo, papel este que, no entanto, depende mais da assunção de um outro tipo de responsabilidades, quer por parte de entidades tão abstratas como a sociedade e o sistema educativo, quer por parte de entidades exteriores aos docentes como o Ministério da Educação, os Serviços de Psicologia e Orientação ou as Associações de Pais. Dependeria deste investimento a possibilidade das escolas responderem de forma mais capaz às solicitações que lhes são feitas, condição necessária para que os professores pudessem encontrar um sentido mais gratificante para as ações que, enquanto docentes, protagonizam. Esta perspetiva, que poderá ser caracterizada como uma perspetiva inconsequente, acaba por contribuir, afinal, para agravar o desencanto profissional dos professores, no momento em que impede a formulação de alternativas que sejam, pelo menos, tanto quanto possível, exequíveis. Embora, e ao contrário dos discursos conservadores, os discursos de natureza corporativa recusem que o mal-estar docente se resolva à custa da exclusão escolar dos alunos, isso não significa, contudo, que não entendam também a gestão e a resolução dessa crise como algo exterior à ação dos professores, dependente, por isso e também, de um conjunto de medidas políticas a adotar. Medidas que, em geral, se relacionam quer com questões de carácter social, quer com questões de carácter económico ou com questões mais específicas de natureza sectorial, nos domínios, por exemplo, da proteção à maternidade e à infância ou ainda nos domínios da assistência social e da justiça. Medidas que dizem respeito, igualmente, ao apetrechamento material das escolas, à organização das turmas ou à melhoria das condições de trabalho e do estatuto profissional dos docentes. Sem se pretender discutir a importância de tais medidas e o modo como estas poderão afetar o funcionamento das escolas e, por consequência, a vida profissional dos professores, há que discutir se são essas medidas que permitem, só por si, que as escolas se transformem em espaços educativos e culturais mais pertinentes e mais credíveis. É de esperar que sim, embora seja necessário equacionar até que ponto o 
facto de não ocorrerem, igualmente, transformações ao nível das práticas educativas dos professores, nesses contextos agora melhor apetrechados, permite que os problemas confrontados pelas escolas e os docentes possam ser resolvidos de forma satisfatória e gratificante. O problema dos discursos de natureza corporativa não tem a ver, então, com o tipo de reivindicações que protagoniza, mas com o estatuto o qual é atribuído a essas reivindicações e ao impacto das mesmas tanto no que diz respeito às atividades educativas que as escolas animam, quanto no que diz respeito à (re)configuração da intervenção curricular e pedagógica dos professores e à definição da profissão docente.

Pode afirmar-se, então, que o maior problema defrontado por nós face aos argumentos invocados, quer pelos discursos conservadores quer pelos discursos de natureza corporativa, dizem respeito ao modo como ignoram a configuração tradicional do modelo de educação escolar enquanto variável decisiva a ter em conta na discussão sobre a profissão e o exercício da atividade profissional dos professores. E ignoram-no, num caso e no outro, em função da sua aceitação tácita quanto aos pressupostos e à estrutura que o fundamentam, bem como quanto ao papel que aos professores compete assumir neste âmbito. Trata-se de uma variável da reflexão sobre a profissão docente que, neste âmbito, não poderá ser negligenciada.

Num registo distinto daquele que é veiculado pelos discursos de pendor fatalista, os quais acabamos de identificar de forma sumária, emergem os discursos de natureza voluntarista e os discursos que se enquadram num campo o qual tende valorizar a reflexividade docente como a sua matriz de referência.

Poder-se-á considerar que os primeiros são a antítese dos discursos fatalistas, já que atribui um papel nuclear e decisivo aos professores, quer na promoção de atividades relacionadas quer com a construção do "partenariado educativo" (CORREIA, MATOS, 2001, p. 39), resultante da "mitificação de um comunitarismo educativo ingénuo que dissimula as desigualdades - para as pensar como diferenças" (idem) com a adoção de práticas pedagógicas e didáticas que, nesta perspetiva, dependem, 
apenas e sobretudo, das "competências éticas - capazes de assegurar o respeito e a tolerância relativamente à diferença - e de competências técnico-pedagógicas e organizacionais" (idem, p. 40) dos docentes para se afirmarem como respostas educativas inquestionavelmente redentoras. É este quadro conceptual que é objeto da denúncia de Nóvoa (2005), o qual se refere ao transbordamento de funções das escolas como um obstáculo à sua afirmação como espaço de produção e afirmação cultural, no momento em que as finalidades culturais das escolas tendem a subordinarse aos objetivos relacionados com a inclusão social dos seus alunos. Não havendo, à partida, qualquer incompatibilidade entre os primeiros e os segundos, há que reconhecer, no entanto, que não é por via da desvalorização da sua dimensão cultural que as escolas cumprem as suas funções sociais. Se esta é, na minha opinião, uma narrativa que impede a Escola de se afirmar como um instrumento de empoderamento cultural, importa chamar a atenção para uma outra, a qual tem a ver com a hiperresponsabilização dos professores pela gestão dos problemas educativos e sociais das comunidades em que vivemos.

Os discursos que decorrem da afirmação da possibilidade dos docentes se afirmarem como profissionais reflexivos funda-se noutros pressupostos e noutras opções quanto ao modo como se identificam os sentidos e as finalidades da educação escolar, o que se entende por aluno, o que se define por ensinar ou por aprender e, neste âmbito, o que se configura por currículo e gestão do currículo, por organização do trabalho de aprendizagem e dos dispositivos de medição pedagógica ou por avaliação e dispositivos de avaliação.

É, pois, no âmbito deste espaço de reflexão sobre a profissão docente que se discute, então, qual é a margem de manobra dos professores no âmbito do processo de definição e afirmação da sua profissão num tempo tão paradoxal como aquele em que vivemos. Daí que se pergunte: Como é que os professores podem responder ao excesso de atribuições políticas, sociais, culturais e educativas a que se dizem sujeitos e lidam, simultaneamente, com a desconfiança, tantas vezes, sentida por eles? 
Como é que se podem gerir, em termos profissionais, os novos desafios a serem enfrentados relacionados com a crescente massificação da Escola e a subsequente heterogeneização do seu corpo discente e com a maior responsabilização social deste contexto educativo, decorrente da perda de influência de alguns dos dispositivos tradicionais de regulação social mais prestigiados (a família, a igreja, a comunidade, etc.) e do papel de mediação que aquela mesma Escola assume, graças à sua função certificativa, entre os indivíduos e o mercado de trabalho?

Que outras respostas é que se podem encontrar, em termos do exercício da profissão docente, para lidar com a concorrência das novas tecnologias de comunicação e dos meios informáticos que temos hoje ao nosso dispor?

Que outras respostas é que se podem encontrar para enfrentarem o divórcio existente entre o que se aprende nas escolas e as necessidades e exigências das sociedades contemporâneas?

Como é que se pode lidar e quais outras respostas podem ser encontradas para se relacionarem com crianças e jovens cuja socialização ocorre em função de padrões sociais menos coercivos e sujeitos a um conjunto de experiências pessoais, sociais e culturais assaz distintas daquelas outras experiências que os seus professores viveram?

Estas são questões colocadas para que se possa discutir se os professores estão inevitavelmente condenados a fazer mal o seu trabalho ou se terão que repensar, antes, a sua atividade profissional em função de outras preocupações, de um novo conjunto de compromissos e de um novo tipo de dilemas profissionais que os conduzem a encontrar e/ou a aceitar um novo corpo de referenciais teóricos, capazes de sustentar a assunção de práticas educativas congruentes com tais preocupações, tais compromissos, tais dilemas e, finalmente, tais referenciais.

É no âmbito deste debate que a valorização dos professores como profissionais reflexivos constitui um movimento que corresponde, por um lado, à denúncia das limitações e dos equívocos da racionalidade técnico-científica e, por outro, à afirmação política e socioprofissional dos docentes (SCHÖN, 1995; STENHOUSE, 1984; CARR, KEMMIS, 1988; 
GIROUX, 1990; ZEICHNER, 1993; ALARCÃO, 1996; PERRENOUD, 2001; 2002). Neste sentido, e de acordo com esta perspetiva, recusa-se quer a conceção em função da qual se defende que a ação do professor consiste, sobretudo, na aplicação de decisões técnicas quer a crença de que a noção de conhecimento subjacente a este tipo de ação se assume como o guia que decide e prescreve as práticas, pelo fato de se partir do princípio que é possível estabelecer previamente tanto os resultados que se pretendem obter como as próprias atividades que permitem obtê-los. Trata-se de uma recusa que é legitimada pelo fato de se reconhecer que as situações educativas que enfrentam não são, muitas vezes, passíveis de ser previamente apreendidas, obrigando ao improviso, à valorização da intuição e à utilização de procedimentos heterodoxos e não validados, adquiridos por via da prática concreta que os professores foram desenvolvendo ao longo dos anos de experiência profissional. Nem sempre os desafios e as situações vividas pelos professores podem ser avaliados e enfrentados em função das categorias e das soluções previamente estabelecidas pela investigação, daí que seja necessário reconhecer e valorizar a capacidade de reflexão dos professores como competência necessária ao exercício das suas funções e, por via disso, como propriedade a ter em conta na reconfiguração da profissão docente. É que deixou de ser possível continuar a pensar na Escola como um espaço sujeito a rotinas, gerido sem sobressaltos, que se desenvolve de forma previsível e garante a sabedoria e a competência daqueles que a frequentam e constitui um sinal de esperança no sentido da resolução dos problemas da humanidade. Deixou de ser possível, por isso, definir consensos acerca das finalidades da Escola que se vê confrontada com solicitações contraditórias. Deixou de ser possível, igualmente, impor soluções inquestionáveis sem custos em escolas, e sociedades, onde a "autoridade tradicional é contestada: nem os alunos nem os professores se contentam em obedecer só porque a ordem vem de cima" (PERRENOUD, 2001, p. 38). Deixamos de possuir ou, pelo menos, de acreditar que possuímos soluções pronto-a-vestir para os desafios, os dilemas e as exigências que se colocam a todos os que participam na vida das escolas, nomeadamente os professores. 
É perante o quadro descrito que se pode compreender melhor as limitações da racionalidade técnico-científica, particularmente quando esta tende a desvalorizar e a subestimar o que Schön designa por "epistemologia da prática" (SCHÖN, 1995, p. 20), em função da qual se desenvolve a conceção de profissional reflexivo, aquele que é capaz de enfrentar e resolver situações inéditas acionando um conjunto de saberes adquiridos de forma tácita no confronto com os problemas da prática ao partir, em primeiro lugar, do conhecimento que se obtém agindo (o conhecimento na açãoº $)$ e, simultaneamente, da reflexão que ocorre no decurso da ação, de forma a poder monitorizar-se a validade dos procedimentos que se acionam (reflexão na ação ${ }^{3}$ ), e em segundo lugar, partindo quer da reflexão retrospetiva sobre a sua atuação e os resultados obtidos (reflexão sobre a ação $0^{4}$ ) quer da "reflexão sobre a reflexão na ação" (ALARCÃO, 1996, p. 17), a qual corresponde a uma espécie de operação de ponderação e sistematização do conhecimento adquirido, um genuíno processo de construção do saber que liberta o profissional da informação que os outros lhe impõem, para a integrar e reconfigurar num todo coerente, capaz, por um lado, de contribuir para a interpelação do conhecimento já adquirido e, por outro, de ajudar "a determinar ações futuras, a compreender futuros problemas ou a descobrir novas soluções" (idem).

É esta crença fundamentada no professor como profissional reflexivo que adquire uma importância inequívoca quando, perante situações mais complexas, ou pelo menos reconhecidas como tal, se exige práticas profissionais congruentes que possam fazer frente a situações incertas, ambíguas ou conflituais, práticas que não possam ser objeto de algoritmização ou de raciocínios lineares. É no âmbito deste contexto que a conceção do professor como profissional reflexivo se revela como uma conceção promissora tanto do ponto de vista praxeológico quanto do ponto de vista da discussão acerca da profissão docente e da definição

\footnotetext{
2 “Knowing-in-action" (SCHÖN, 1995, p.50).

3 "Reflecting-in-action" (SCHÖN, 1995, p.54).

4 “Reflecting-in-practice” (SCHÖN, 1995, p.59).
} 
das suas propriedades no mundo em que vivemos. Trata-se de um outro modo de entender a profissão, o qual conduz a uma definição de autonomia profissional que se assume mais pela sua dimensão educativa do que pela sua dimensão corporativa, na medida em que contribui para redefinir os termos da intervenção docente, bem como os estatutos e os papéis dos atores envolvidos, de forma mais ou menos direta, no processo de educação escolar.

O que se constata é que as intervenções educativas que entendem o ato de educar como educare (alimentar) não necessitam que os professores se afirmem como profissionais reflexivos, quando se sabe que, de acordo com uma tal racionalidade educativa, o ato de ensinar é entendido como um ato de difusão de um conhecimento pré-fabricado e de imposição de normas e convenções exteriores aos sujeitos que aprendem, enquanto o ato de aprender se circunscreve, sobretudo, a um processo por meio do qual se acede a um saber exterior ao sujeito.

É face a um outro modo de entender o ato de educar como educere (conduzir) que a possibilidade da ação docente se afirmar por via da reflexividade dos professores se torna numa necessidade profissional, já que o ato de ensinar deixa de ser identificado como uma operação de formatação educativa para passar a ser abordado por via de um processo. Este apoia os alunos a contactarem e a confrontarem-se com informações, instrumentos e atividades relevantes no âmbito da relação que estes estabelecem com uma dada realidade, com os outros e com o património cultural disponível, enquanto o Ato de aprender passa a ser definido como um processo que se inicia a partir do contato e/ou do confronto que se estabelece entre a realidade objetivável e o conjunto de significados que cada um constrói acerca dessa mesma realidade; entre as representações e conceções prévias que cada um aciona perante um dado fenómeno e as representações e as conceções que culturalmente se encontram disponíveis para apreender esse mesmo fenómeno; entre as experiências individuais e a estrutura das regras sociais pré-existentes; entre si e os outros com os quais se partilham vivências e atividades. Neste caso, o que se pretende é propor uma prática pedagógica que suscite a visão de rede, de teia, de 
interdependência (BEHRENS, 2011) e que, concomitantemente, permita que os alunos se assumam como coprotagonistas do processo de aprendizagem que lhes diz respeito.

Em suma, é no âmbito de um paradigma educativo que se entende o educar como equivalente a alimentar, que se afigura como mais congruente a afirmação dos pressupostos, que subjazem à afirmação da racionalidade técnico-científica, em função da qual se espera não a apropiação dos professores como profissionais reflexivos, mas que sejam capazes de discernir quais os reportórios pedagógicos e didáticos mais adequados que a investigação disponibiliza para responder aos desafios profissionais que foram colocadas a eles. Dito isto, compreende-se melhor que a assunção dos professores como profissionais reflexivos, em função da qual se configura uma genuína conceção de autonomia profissional, depende da opção por abordagens pedagógicas que, de um modo geral, se caracterizem por:

- entender a influência educativa dos professores como um ato de interlocução qualificada que se afirma ao nível da organização social do espaço, do tempo e dos instrumentos da aprendizagem, bem como ao nível do apoio necessário que se promove e organiza para que os alunos aprendam e aprendam a aprender;

- entender os alunos como parceiros decisivos no âmbito de uma intervenção educativa onde professores e alunos participam a seu modo, já que o saber é o resultado de um processo de reconstrução pessoal que ocorre através de um processo de interações socioculturais, o qual não poderá ignorar esses alunos como coprotagonistas incontornáveis a valorizar no âmbito de um tal processo;

- não dissociar a formação pessoal e social dos alunos da apropriação do património cultural disponível, já que na Escola a possibilidade de concretizar a primeira é determinada pela qualidade das interações que esses alunos estabelecem com o segundo. 
Será de acordo com estes pressupostos que a reflexividade docente constitui, então, uma garantia da possibilidade de se realizar interlocuções qualificadas e necessariamente singulares entre os professores e os seus alunos, as quais possam estimular a emergência do que Philippe Meirieu designa por "momento pedagógico" (MEIRIEU, 2002, p. 57), o momento em que o professor compreende como a resistência dos alunos a aprender implica que o professor, mais do que proceder à sua aniquilação, "comece por reconhecer a legitimidade dessa resistência de forma a lidar com ela e fazendo da mesma uma condição pedagógica a respeitar" (FERNANDES, 2003, p. 645) para promover um encontro, através do qual possa

Explorar sem tréguas os obstáculos inerentes ao seu próprio discurso, circunscrever as formulações aproximativas, buscar incansavelmente exemplos e dispositivos novos, multiplicar as reformulações inventivas, as «mudanças de quadro», como dizem os especialistas em didática da Matemática ou as «descontextualizações», como dizemos nós (MEIRIEU, 2002, p. 80).

Um encontro que permita "oferecer um objeto de saber de que o outro possa apoderar-se, para examiná-lo, para pegá-lo nas mãos, para manipulá-lo, para apropriar-se dele ou desvirtuá-lo, enfim, para pôr «algo de si nele»" (idem), já que, assim, o professor terá "multiplicado os "pontos de apoio» e aberto perspetivas que constituirão os meios para o aluno exercer a sua inteligência" (idem).

Como realizar um tal projeto dissociado de um processo de afirmação da reflexividade dos professores? Como é que se entende que um "momento pedagógico" se concretize - um momento em que os professores aceitam ser surpreendidos e tocados pela estranheza que os seus alunos possam revelar perante um discurso que recusam ou não compreendem - sem ter em conta a capacidade de reflexão dos professores sobre o saber e os obstáculos de carácter epistemológico que se interpõem entre este e os seus alunos? Como é que se entende que um "momento pedagógico" se concretize se não se valorizar a capacidade de reflexão dos 
professores para compreender e agir perante as posturas intelectuais e relacionais desses mesmos alunos?

A reflexividade docente assume-se, assim, como uma particularidade daqueles professores que, em primeiro lugar, reconhecem que, apesar de toda a sua sabedoria, da sua experiência e dos seus esforços jamais serão capazes de prever e de programar quaisquer sequências de aprendizagem por meio das quais se antecipe e preveja a resistência dos alunos a aprender, "uma resistência, por definição imprevisível, do aluno que recusa, ignora, contesta, rejeita o que lhe é proposto" (idem, p. 59). Uma resistência que esses professores aceitam é constituir um sinal de alerta em função do qual deverão repensar e reorganizar o processo de intervenção educativa que vão animando. Em segundo lugar, a reflexividade docente é, igualmente, uma dimensão fundamental daquelas conceções, relativas à ação profissional dos professores, em função das quais se afirma que esta ação não pode ficar refém dos equívocos da racionalidade técnico-científica, nomeadamente quando esta se invoca para se afirmar que são os saberes e os reportórios que outros lhes propõem a partir da investigação, onde os docentes não participam, que deverão determinar a ação que estes deverão protagonizar.

De acordo com a perspetiva daqueles que entendem a necessidade dos docentes se afirmarem como profissionais reflexivos assenta sobre quatro pressupostos fundamentais:

a) Um primeiro pressuposto através do qual se afirma a importância política, social e educativa da instituição escolar no mundo e nas sociedades contemporâneas, hoje caracterizadas como sociedades do conhecimento (HARGREAVES, 2003);

b) Um segundo pressuposto através do qual se afirma o potencial democrático da educação escolar, o que, neste caso, significa que a Escola pode contribuir para que, pelo menos, se tomem "todas as medidas necessárias para dar aos mais desfavorecidos boas condições de formação e contrariar todos os mecanismos que conduzem a colocá-los nas piores" (BOURDIEU, 1987, p. 107); 
c) Um terceiro pressuposto através do qual se recusa entender a crise da escolarização como uma crise, de algum modo, exterior aos professores, à sua reflexão e à sua ação como profissionais e docentes;

d) Um quarto pressuposto, através do qual se considera que a alegada crise da escolarização é uma oportunidade para se questionar o ofício do aluno, o ofício do professor e os modos como ambos os ofícios se articulam e se co-definem.

É face ao conjunto de pressupostos acabados de definir que a reflexão sobre os novos sentidos para a profissão docente implica, da parte dos professores, uma ruptura com o modelo de formação consagrado pelo "paradigma pedagógico da instrução" (TRINDADE, COSME, 2010, p. 28), obrigando os professores a enfrentar, à sua dimensão, as contradições entre uma Escola que continua a definir-se como um espaço de transmissão de saberes e da produção de comportamentos estandartizados e um mundo plural que exige, cada vez mais, que sejamos capazes de reconstruir os saberes que herdamos e de reflectir sobre eles, de construir consensos inéditos que nenhum período de treino prévio nos poderá ensinar a realizar ou de assumir uma postura eticamente mais exigente face a nós próprios, aos outros e à comunidade em que nos inserimos.

\section{Considerações finais}

\section{O espaço da ação profissional dos professores}

É de acordo com a reflexão acabada de propor, que importa afirmar que o espaço da ação profissional dos professores é o das atividades de mediação curricular e pedagógica que estes desenvolvem, os quais, por isso, terão que ser entendidos como a dimensão nuclear do processo de redefinição do trabalho docente. Não se nega a importância das atividades relacionadas com tarefas administrativas e pedagógicas, as atividades relacionadas com o trabalho realizado com atores e instâncias exteriores às escolas, o trabalho com outros docentes e mesmo as atividades de 
assessoria e consultadoria pedagógicas, desde que este conjunto de atividades se subordine às atividades de mediação curricular e pedagógica, as quais constituem o núcleo identitário em função do qual se configura a profissão docente. Uma profissão que, como defendemos neste texto, exige dos professores, tendo em conta os desafios cotidianos que se vivem nas respetivas salas de aula, terá de ser pensado de forma a que os profissionais que a abraçam possam participar na construção do conhecimento profissional que lhes diz respeito, o que os conduz, por isso, a assumirem um papel mais decisivo na construção de coletivos profissionais que reflitam sobre o que se passa ou o que se poderá vir a passar, naquelas salas de aula, de forma mais colegial, sustentada e refletida.

\section{Referências}

ALARCÃO, I. Reflexão crítica sobre o pensamento de D. Schön e os programas de formação de professores. In: ALARCÃO, I. (Org.), Formação reflexiva de professores: estratégias de supervisão. Porto: Porto Editora, 1996. p. 11-30.

BAUDELOT, C.; ESTABLET, R. La escuela capitalista en Francia. Madrid: Siglo XXI, 1975.

BEHRENS, M. A. Paradigma da complexidade: metodologia de projetos, contratos didáticos e portfólios. Petrópolis: Editora Vozes, 2011.

BOURDIEU, P. Propostas para o ensino do futuro. Cadernos de Ciências Sociais, n. 5, p. 101-119, 1987.

BOURDIEU, P.; PASSERON, J.-C. La reproducción: elementos para una teoría del sistema de enseñanza. Madrid : Editorial Popular, 2001.

CARR, W.; KEMMIS, W. Teoría crítica de la enseñanza: la investigación-acción en la formación del profesorado. Barcelona: Ediciones Martínez Roca, 1988.

CORREIA, J. A.; MATOS, M. Solidões e solidariedades nos quotidianos dos professores. Porto: Edições ASA, 2001. 
CORTESÃO, L. Ser professor: um ofício em vias de extinção - reflexões sobre práticas educativas face à diversidade no limiar do séc. XXI. Porto: Edições Afrontamento, 2000.

FERNANDES, R. E. T. Escola e influência educativa: o estatuto dos discursos didácticos inovadores no $1^{\circ}$ ciclo do ensino básico. 2006. $688 \mathrm{f}$. Tese (Doutorado em Educação) - Faculdade de Psicologia e de Ciências da Educação da Universidade do Porto, Porto, 2003.

GIROUX, H. Los professores como intelectuales: hacia una pedagogía crítica del aprendizage. Madrid: Ediciones Paidós, 1990.

HARGREAVES, A. O ensino na sociedade do conhecimento: a educação na era da insegurança. Trad. Roberto Cataldo Costa. Porto: Porto Editora, 2003.

MEIRIEU, P. A pedagogia: entre o dizer e o fazer. Trad. Regina Garcez. Porto Alegre: Artes Médicas, 2002.

NÓVOA, A. Eu pedagogo me confesso: diálogos com Rui Grácio. Inovação, v. 14, n. 1-2, p. 9-33, 2001.

NÓVOA, A. Evidentemente: Histórias da Educação. Porto: Edições ASA, 2005.

PERRENOUD, P. Ofício de aluno e sentido do trabalho escolar. Trad. Maria Isabel Lopes. Porto: Porto Editora, 1995.

PERRENOUD, P. Ensinar: agir na urgência, decidir na incerteza. Trad. Claudia Schilling. 2.ed. Porto Alegre: ARTMED Editora, 2001.

PERRENOUD, P. A prática reflexiva no ofício de professor: profissionalização e razão pedagógica. Trad. Claudia Schilling. Porto Alegre: ARTMED Editora, 2002.

SCHÖN, D. A. The reflective practitioner: how professionals think in action. New York: Basic Books, 1995.

TRINDADE, R.; COSME, A. Escola, educação e aprendizagem: desafios e respostas pedagógicas. Rio de Janeiro: WAK Editora, 2010. 
STENHOUSE, L. Investigación y desarrollo del curriculum. Madrid: Ediciones Morata, 1984.

ZEICHNER, K. M. A formação reflexiva de professores: idéias e práticas. Lisboa: Educa - Professores, 1993.

Recebido: 10/08/2016

Received: 08/10/2016

Aprovado: 30/08/2016 Approved: 08/30/2016 